\title{
In reply: Ultrasound-guided internal jugular vein cannulation: a novel technique for confirming that the guidewire is directed towards the right atrium
}

\author{
Kazuyoshi Aoyama, MD • Ichiro Takenaka, MD
}

Received: 13 October 2015/ Accepted: 14 October 2015/Published online: 28 October 2015

(C) Canadian Anesthesiologists' Society 2015

\section{To the Editor,}

We appreciate the additional comments by Drs Maheshwari regarding our report addressing confirmation of guidewire placement during central venous cannulation. ${ }^{1}$ They suggest a useful method for further confirmation of the position of the guidewire. With their approach, the ultrasound probe is placed at the supraclavicular fossa and tilted posteroinferiorly towards the thoracic cavity, which allows confirmation of the location of the guidewire within the lumen of the brachiocephalic vein. We agree that their technique helps to detect the guidewire within the brachiocephalic vein and provides some useful information. Nevertheless, further study would be needed to confirm whether this maneuver would be able to prevent catheter misplacement-e.g., in the vertebral vein ${ }^{2}$ or the azygos vein. ${ }^{3}$

\section{Conflicts of interest None declared.}

Funding Support was provided solely from institutional and/or departmental sources.

\section{References}

1. Aoyama K, Takenaka I, Iwagaki T, Sano H. A simple maneuver for confirmation of the guidewire during ultrasound-guided internal jugular vein cannulation. Can J Anesth 2015; 62: 839-40.

2. Yang SH, Jung SM, Park SJ. Misinsertion of central venous catheter into the suspected vertebral vein: a case report. Korean J Anesthesiol 2014; 67: 342-5.

3. Calvino J, Bravo J, Martinez L, Millan B, Pulpeiro JR. Recognizing misplacement of a dialysis catheter in the azygos vein. Hemodial Int 2013; 17: 455-7.

K. Aoyama, MD ( $₫)$

Department of Anesthesia, Kitakyushu General Hospital,

Kitakyushu, Japan

e-mail: kazuyoshi.aoyama@kitakyu-hp.or.jp

I. Takenaka, MD

Department of Anesthesia, Kyushu Rosai Hospital, Kitakyushu,

Japan 